\section{Author Correction: Human neocortical expansion involves glutamatergic neuron diversification}

https://doi.org/10.1038/s41586-021-04322-4

Published online: 6 January 2022

Correction to: Nature https://doi.org/10.1038/s41586-021-03813-8

Published online 6 October 2021

Open access

Check for updates

Jim Berg, Staci A. Sorensen, Jonathan T. Ting, Jeremy A. Miller, Thomas Chartrand, Anatoly Buchin, Trygve E. Bakken, Agata Budzillo, Nick Dee, Song-Lin Ding, Nathan W. Gouwens, Rebecca D. Hodge, Brian Kalmbach, Changkyu Lee, Brian R. Lee, Lauren Alfiler, Katherine Baker, Eliza Barkan, Allison Beller, Kyla Berry, Darren Bertagnolli, Kris Bickley, Jasmine Bomben, Thomas Braun, Krissy Brouner, Tamara Casper, Peter Chong, Kirsten Crichton, Rachel Dalley, Rebecca de Frates, Tsega Desta, Samuel Dingman Lee, Florence D'Orazi, Nadezhda Dotson, Tom Egdorf, Rachel Enstrom, Colin Farrell, David Feng, Olivia Fong, Szabina Furdan, Anna A. Galakhova, Clare Gamlin, Amanda Gary, Alexandra Glandon, Jeff Goldy, Melissa Gorham, Natalia A. Goriounova, Sergey Gratiy, Lucas Graybuck, Hong Gu, Kristen Hadley, Nathan Hansen, Tim S. Heistek, Alex M. Henry, Djai B. Heyer, DiJon Hill, Chris Hill, Madie Hupp, Tim Jarsky, Sara Kebede, Lisa Keene, Lisa Kim, Mean-Hwan Kim, Matthew Kroll, Caitlin Latimer, Boaz P. Levi, Katherine E. Link, Matthew Mallory, Rusty Mann, Desiree Marshall, Michelle Maxwell, Medea McGraw,
Delissa McMillen, Erica Melief, Eline J. Mertens, Leona Mezei, Norbert Mihut, Stephanie Mok, Gabor Molnar, Alice Mukora, Lindsay Ng, Kiet Ngo, Philip R. Nicovich, Julie Nyhus, Gaspar Olah, Aaron Oldre, Victoria Omstead, Attila Ozsvar, Daniel Park, Hanchuan Peng, Trangthanh Pham, Christina A. Pom, Lydia Potekhina, Ramkumar Rajanbabu, Shea Ransford, David Reid, Christine Rimorin, Augustin Ruiz, David Sandman, Josef Sulc, Susan M. Sunkin, Aaron Szafer, Viktor Szemenyei, Elliot R. Thomsen, Michael Tieu, Amy Torkelson, Jessica Trinh, Herman Tung, Wayne Wakeman, Femke Waleboer, Katelyn Ward, René Wilbers, Grace Williams, Zizhen Yao, Jae-Geun Yoon, Costas Anastassiou, Anton Arkhipov, Pal Barzo, Amy Bernard, Charles Cobbs, Philip C. de Witt Hamer, Richard G. Ellenbogen, Luke Esposito, Manuel Ferreira, Ryder P. Gwinn, Michael J. Hawrylycz, Patrick R. Hof, Sander Idema, Allan R. Jones, C. Dirk Keene, Andrew L. Ko, Gabe J. Murphy, Lydia Ng, Jeffrey G. Ojemann, Anoop P. Patel, John W. Phillips, Daniel L. Silbergeld, Kimberly Smith, Bosiljka Tasic, Rafael Yuste, Idan Segev, Christiaan P. J. de Kock, Huibert D. Mansvelder, Gabor Tamas, Hongkui Zeng, Christof Koch \& Ed S. Lein

In the version of this Article initially published, the Acknowledgements statement contained an error. Originally appearing with thanks for support given in part as follows, "R01EY023173 from The National Eye Institute, U01MH105982 from the National Institute of Mental Health and Eunice Kennedy Shriver National Institute of Child Health \& Human Development, and R011EY023173 from The National Institute of Allergy and Infectious Disease," the last number (R011EY023173) was mistakenly added and is not in fact a grant or one provided by the NIAID. The mention has been removed.

The changes have been made to the online version of the Article.

(i) Open Access This article is licensed under a Creative Commons Attribution 4.0 International License, which permits use, sharing, adaptation, distribution and reproduction in any medium or format, as long as you give appropriate credit to the original author(s) and the source, provide a link to the Creative Commons license, and indicate if changes were made. The images or other third party material in this article are included in the article's Creative Commons license, unless indicated otherwise in a credit line to the material. If material is not included in the article's Creative Commons license and your intended use is not permitted by statutory regulation or exceeds the permitted use, you will need to obtain permission directly from the copyright holder. To view a copy of this license visit http://creativecommons.org/licenses/by/4.0/.

(c) The Author(s) 2022 